\title{
Pressure Law of Roof and Supporting Technology of Roadway When Working Face Passing through Abandoned Roadway
}

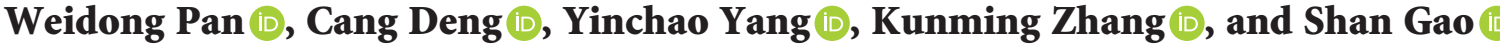 \\ School of Energy and Mining Engineering, China University of Mining and Technology, \\ Kailuan (Group) Limited Liability Corporation, 063000), Beijing 100083, China
}

Correspondence should be addressed to Kunming Zhang; 499452168@qq.com

Received 14 September 2021; Revised 2 December 2021; Accepted 3 February 2022; Published 3 March 2022

Academic Editor: Antonio Giuffrida

Copyright ( 2022 Weidong Pan et al. This is an open access article distributed under the Creative Commons Attribution License, which permits unrestricted use, distribution, and reproduction in any medium, provided the original work is properly cited.

Unlike conventional long-wall mining, the roofing activity is more intense when the long-wall face passes through the abandoned roadway. Technically, the coal pillar between the abandoned roadway and the long-wall face will suddenly fail with a certain critical value of its width, leading to the roof breaks in advance and other production-restricted problems because of the support loss, which will be a great threat to underground mining activities. In order to guarantee safe mining conditions, it is a great necessity to uncover how the roof breaks in advance and how to deal with it. From the stability maintaining of the key block perspective, this study looked at research from the 12404-1 long-wall face of Wulanmulun coal mine, China. The critical value of the coal pillar's width was determined to be about $4.75 \mathrm{~m}$ by theoretical analysis, and likely, the appropriate supporting force of the abandoned roadway's roof is about $1073 \mathrm{kN}$ per meter. In this study, a numerical simulation method was adopted to study the ground pressure when the long-wall face is passing through the abandoned roadway. Correspondingly, a compound supporting technology involving the roof presplit technique, anchor cable supporting, and pumping pillar supporting was proposed for the roof of the abandoned roadway, and it practically worked well.

\section{Introduction}

In China, underground mining plays an important role in the exploitation of coal resources, more than 3 billion tons of coal is extracted from underground mines every year, and thousands of kilometers of roadway is tunneled to extract such amount of coal. These roadways play a functional role in coal mine production: a few are used for transportation, while others are used for ventilation. Some of these roadways will be abandoned when they reached their servicing age. Therefore, it is inevitable to encounter a situation in which these roadways lay in the range of the long-wall face, and the long-wall face must pass through these abandoned roadways for a positive production [1].

However, there are differences in strata behaviors of whether the long-wall face passes through the roadway. In this case, a series of problems will arise, which would terribly restrict the production efficiency of the long-wall face. Numerous engineering practices have verified that the coal pillar located between the long-wall face and the abandoned roadway would suddenly fail when the width of the coal pillar reaches a critical value. Meanwhile, the main roof may break in advance due to the support loss from the coal pillar, resulting in coal rib spalling, support crushing, roof falling, etc. Undoubtedly, these issues could be a great threat to the safety of mining activities. In this area, where stronger ground pressure would occur, many studies have been initiated in the past years [2,3]. Li et al. [4] and Gu et al. [5] studied the relationship between the supports and surrounding rock when the long-wall face passes through the abandoned roadway. Xie et al. [6] studied the ground pressure mechanism when the long-wall face passes through the abandoned roadway. Bai et al. [7, 8] and Zhao and Liu [9] established a mechanical model of the roof advanced breaking when the long-wall face passes through the abandoned roadway. Liu et al. [10-13] analyzed the influencing factors of the roof's advanced breaking when the long-wall face passes through the abandoned roadway. AAM (adjusting the angle method) to pass through the abandoned roadway FRT (filling the roadway technique) to control the 
roof of abandoned roadway, respectively, were proposed in these studies above.

Despite the previous research and the evidence of the existence of advanced breaking, the advanced breaking mechanism of the main roof is still unclear, which hinders the management of support resistance. Moreover, the key block stability of the broken roof strata and its influence on the long-wall face surrounding rock need further analysis and research. In addition, better control of the surrounding rock also is key for safe mining [14-16]. Therefore, it is very important to propose a corresponding supporting technology to the roof of the abandoned roadway.

Considering these issues remained, in this study, the mechanism of the roof advanced breaking is revealed and a theoretical model is established to analyze the stability of the key block when long-wall face passes through the abandoned roadway; the ground pressure and the advanced breaking mechanism of the roof are further studied by DEM numerical simulation; a new abandoned roadway supporting technology is proposed to control the stability of the longwall face, and to verify this new support design, the support resistance is monitored when the long-wall face passes through the abandoned roadway.

\section{Engineering Background}

Wulanmulun coal mine is located in the east of Ordos Plateau, inner Mongolia province, China. Because of the production needs, a 12404-1 long-wall face must be set between the 12404-1 tailgate and the 12404-1 headgate, on the west panel of the 12 \# coal seam. The average thickness of \#12 coal seam is $2.51 \mathrm{~m}$, the coal seam dip is $1^{\circ}$ to $3^{\circ}$, and the average burial depth of \#12 is $115.24 \mathrm{~m}$. The width of the $12404-1$ long-wall face is $113 \mathrm{~m}$, the mining height is $2.8 \mathrm{~m}$, and the advancing length is $542.7 \mathrm{~m}$, as shown in Figure 1. The new long-wall face must pass through eight abandoned roadways to complete the production.

According to the statistics, all these abandoned rectangular roadways were driven with a width of $5 \mathrm{~m}$, and the height is $3 \mathrm{~m}$. The surrounding rock conditions of the 124041 long-wall face are specifically shown in Figure 2.

\section{Theoretical Analysis}

3.1. Determination of the Critical Value of Coal Pillar. When there were abandoned roadways ahead of the working face, the vertical stress $\left(\sigma_{\mathrm{y}}, \mathrm{MPa}\right)$ of the coal pillar is the overlap of the mining-induced stress and the side abutment stress of the roadway. As the working face advances forward, when the vertical stress at a certain position in the overlap reaches the ultimate strength of the coal pillar, the coal pillar will collapse. The whole pressure distribution of the coal pillar is shown in Figure 3.

The front abutment pressure of the long-wall face can be calculated with the following equation [17]:

$$
\sigma_{y 1}=N_{0} e^{2 i x / M(1+\sin \phi / 1-\sin \phi)},
$$

where $\sigma_{y 1}$ is the vertical stress from the long-wall face side, $\mathrm{MPa}$; NO is the self-supporting capacity of the working face, $0.25 \mathrm{MPa} ; i$ is the interlayer friction factor, $0.2 ; M$ is the height of the coal seam, $2.5 \mathrm{~m}$; $x$ is the distance from a certain point ahead to the long-wall face, $m$; and $\phi$ is the internal friction angle, $24^{\circ}$.

When the width of the coal pillar reaches the critical width, the plastic state just ends and the elastic state just begins. For the left of the coal pillar, the value of $x$ is $x 0$, the width of the limit equilibrium zone, which is [18]:

$$
x_{0}=\frac{M \lambda}{2 \tan \phi_{0}} \ln \left(\frac{k \gamma H+c_{0} / \tan \phi_{0}}{c_{0} / \tan \phi_{0}+N_{0} / \lambda}\right)
$$

where $\lambda$ is the lateral pressure coefficient, the ratio of horizontal stress to vertical stress, $0.4 ; k$ is the stress concentration factor, $4 ; \gamma$ is the average bulk density of the overlying strata, $27 \mathrm{kN} / \mathrm{m}^{3} ; H$ is the burial depth of the roadway, $115 \mathrm{~m} ; c_{0}$ is the cohesion on the interface between the coal seam and the roof/floor, $0.2 \mathrm{MPa}$; and $\phi_{0}$ is the friction angle on the interface between the coal seam and the roof/floor, $19^{\circ}$.

Simplifying the roadway as circular, the tangential stress is the vertical stress in the horizontal radial direction of the roadway, that is,

$$
\sigma_{y 2}=\frac{\gamma H}{2}(1+\lambda)\left(1+\frac{r_{1}^{2}}{r^{2}}\right)+\frac{\gamma H}{2}(1-\lambda)\left(1+3 \frac{r_{1}^{4}}{r^{4}}\right)
$$

where $\sigma_{y 2}$ is the vertical stress from the roadway side, $\mathrm{MPa}$; $r 1$ is the radius of the circularized roadway, $2.5 \mathrm{~m}$; and $r$ is the distance from a certain point around the roadway to the center of the simplified circle, $m$.

$\sigma_{y}$ of the coal pillar is the sum of $\sigma_{y 1}$ and $\sigma_{y 2}$, with the shrinkage of the coal pillar, the width of the coal pillar will reach the critical value, the coal pillar will quickly break and go unstable, the coal pillar is only subject to vertical force, and $\sigma_{\mathrm{y}}$ at the central position of the coal pillar just reaches the uniaxial compressive strength $\left(\sigma_{c}, \mathrm{MPa}\right)$, which can be calculated with the following equation:

$$
\sigma_{y}=N_{0} e^{2 i x_{0} / M(1+\sin \phi / 1-\sin \phi)}+\frac{\gamma H}{2}(1+\lambda)\left(1+\frac{4 r_{1}^{2}}{r^{2}}\right)+\frac{\gamma H}{2}(1-\lambda)\left(1+48 \frac{r_{1}^{4}}{r^{4}}\right)
$$




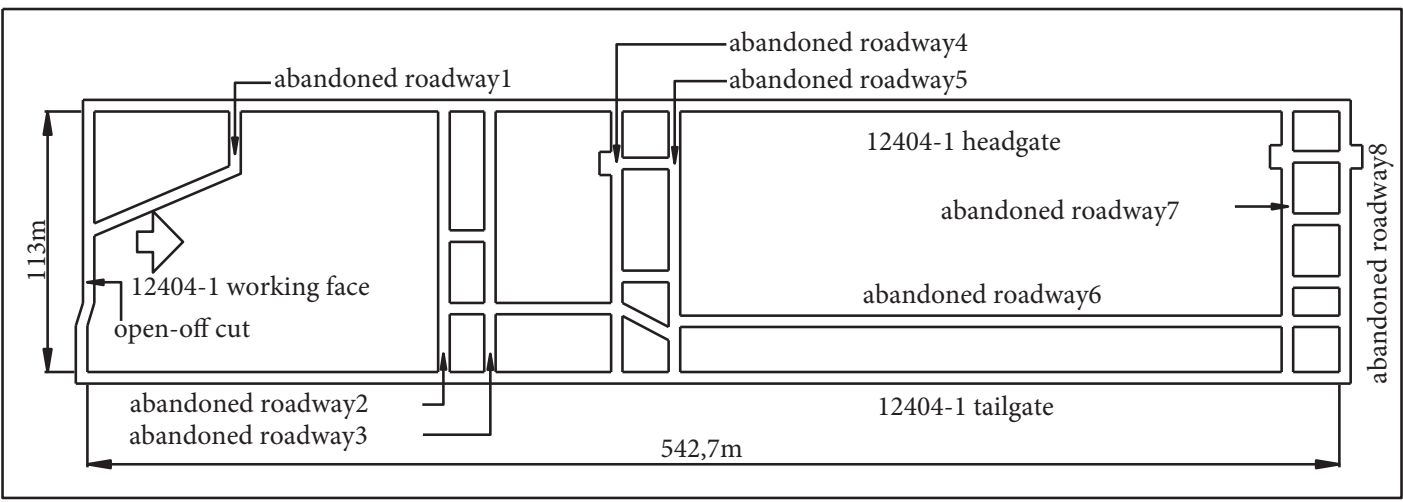

FIgURE 1: Plan layout of 12404-1 long-wall face.

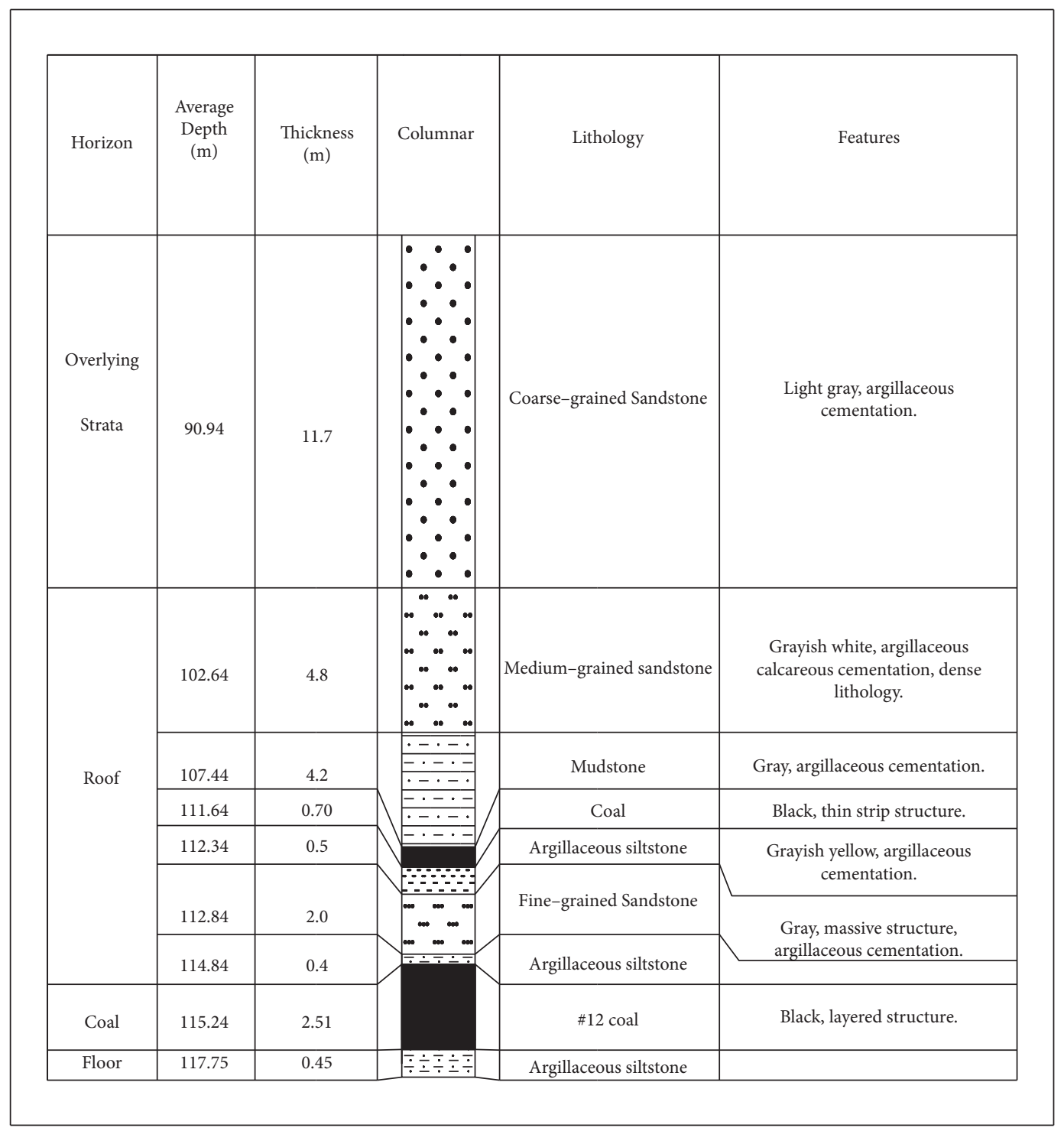

FIgURE 2: Borehole columnar section of 12404-1 long-wall face. 


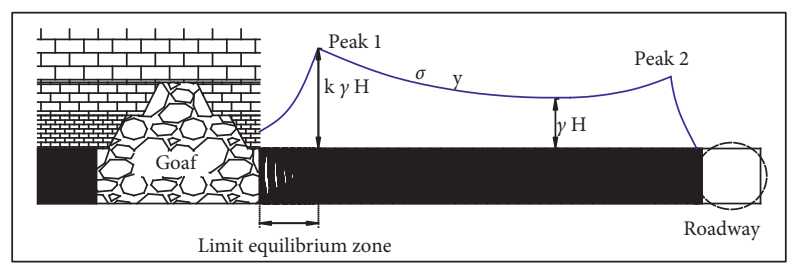

FIgURE 3: Abutment pressure distribution.

Based on the Mohr-Coulomb curve, $\sigma_{c}$ can be calculated with the following equation under unidirectional force:

$$
\sigma_{y}=\sigma_{c}=\frac{2 c \cos \phi}{1-\sin \phi}
$$

where $c$ is the cohesion of coal material, 2.7 MPa.

According to equation (5), $\sigma_{c}$ is about $8.3 \mathrm{MPa}$. Therefore, it can be solved that the critical failure width of the pillar is $x 0+r, 4.75 \mathrm{~m}$.

3.2. Mechanism of the Roof Advanced Breaking. The "Key Stratum" theory proposed by Academician Qian [19] believes that the behavior of overburden of the coal seam complies with the key stratum (KS), which can be a single seam or a thick stratum. After the coal is mined and the immediate roof instantly collapses, the KS begins to bend and break, forming a series of key blocks (KBs).

Generally, when the roof reaches the first weighting interval, it will break and rotate, which is a periodic and stable process. However, if there is an abandoned roadway ahead, the roof-breaking mechanism will drastically change. When the long-wall face passes through the abandoned roadway, the coal pillar's width is gradually narrowed, the unsupported roof span increased, and the coal pillar is changed from the original three-way compression to oneway compression and finally destroyed. When the width of the coal pillar reached the critical value, the roof will suddenly lose the coal pillar's support because of the pillar destruction and abruptly reach or exceed its periodic fracture length, leading to the advanced breaking in which ground pressure appears more intense than the conventional one. Previous similar simulation experiments showed the particularity of passing through an abandoned roadway, as shown in Figure 4. Accordingly, combined with the geology of the Wulanmulun coal mine, we could abstract the similarity models in Figures 5 and 6.

3.3. Stability Analysis of KBs. In order to prevent a series of problems that restrict production and threaten safety, such as coal rib spalling, support crushing, and roadway roof falling caused by the advanced breaking of the roof, from the maintenance of the stability of the $\mathrm{KB}$ perspective, the behavioral law of the overlying strata is analyzed, which could provide a theoretical basis for the roof support.

The hinged rock block hypothesis proposed by a scholar of the former Soviet Union G.N. Kakuznetsov was referred to explain the mechanism. Taking the key block B in Figure 4 as the analysis object, the mechanical balance model where KBs are hinged is established as shown in Figure 7.

Here, $l$ is the advanced breaking length of the main roof, $m ; a$ is the contact height between block $A$ and $C$ and key block $\mathrm{B}, m ; b, c, d$, and $f$, respectively, are the width of the abandoned roadway, the failed coal pillar, the roof control distance, and the length of the key block $B$ above the long-wall face, $m ; \Delta u$ is the rotational subsidence of key block $B, m ; q$ is the load of the overlying strata, calculated value, $12420 \mathrm{kN} / \mathrm{m}$; TAB, RAB, TCB, and $R C B$, respectively, are the horizontal force and shear force applied by key block $\mathrm{A}$ and $\mathrm{C}$ to key block $\mathrm{B}, \mathrm{kN} / \mathrm{m} ; \theta$ is the rotation angle of key block $\mathrm{B},{ }^{\circ} ; h$ is the height of the key block, $m$; $P 1, P 2, P 3$, and $P 4$, respectively, are the supporting force caused by the immediate roof (here we give it $q(x)$ form), residual strength of the failed pillar, hydraulic supporting force, and the needed supporting force on the roof of the abandoned roadway, $\mathrm{kN} / \mathrm{m}$; and $G_{B}$ is the gravity of the key block, $\mathrm{kN}$.

Based on the "S-R" stability theory of masonry beam structure, the key block mainly has two modes of sliding instability and rotation instability [20]. To facilitate the analysis of the stability of the key block, we must make the following assumptions:

(1) Suppose $P 2$ acts on $c / 2, P 3$ acts on $d / 2$, and $R A B=R C B$

(2) Key block B breaks at the limit equilibrium in the coal body

Referring to the balance equation on the force and torque, the following equations are set: 


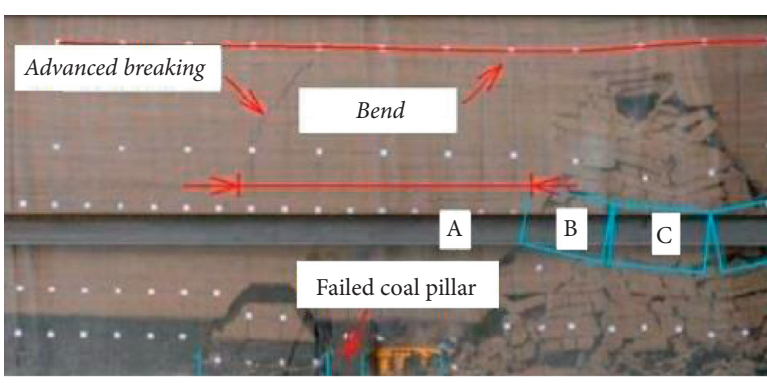

(a)

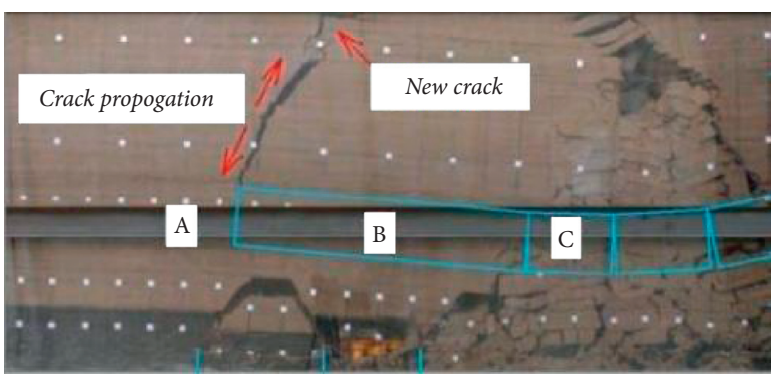

(b)

FIgURE 4: [17] Similar simulation experiment.

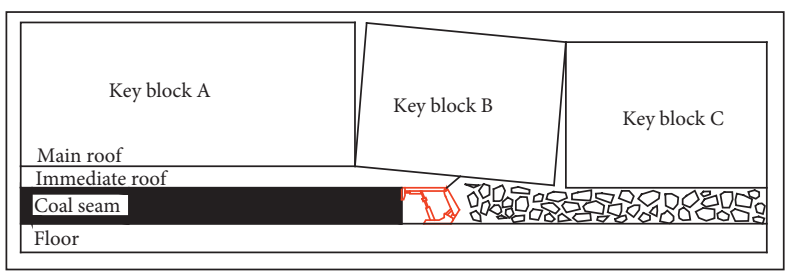

FIGURE 5: Roof breaks without abandoned roadway.

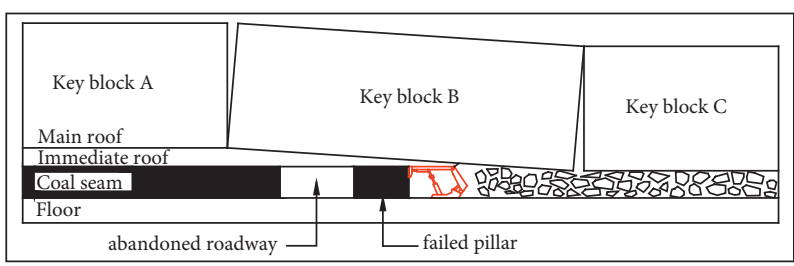

Figure 6: Roof breaks in advance.

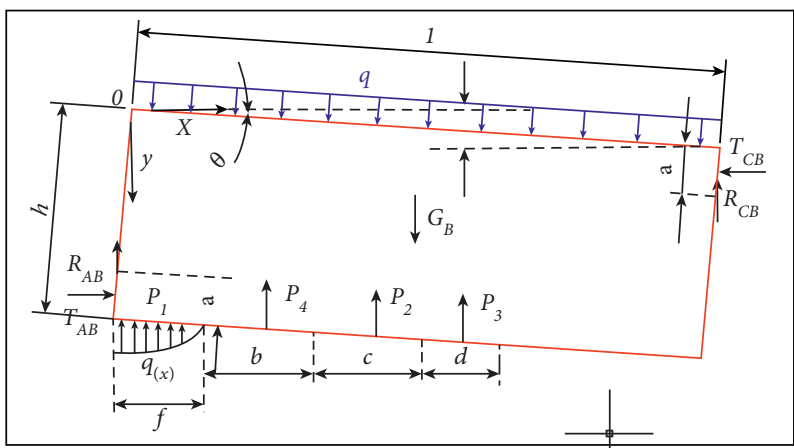

Figure 7: Mechanical model of key block B. 


$$
\begin{aligned}
\sum M_{O}= & 0: T_{A B}\left(h-\frac{a}{2} \cos \theta\right)-T_{C B}\left(\Delta u+\frac{a}{2} \cos \theta\right)-R_{A B}\left(h-\frac{a}{2}\right) \sin \theta \\
& +R_{C B}\left(l \cos \theta-\frac{a}{2} \sin \theta\right) \\
& -\int_{-h \sin \theta}^{0} x q(x) d x+\int_{0}^{f-h \sin \theta} x q(x) d x+P_{2}\left(\frac{c}{2}+b+f-h \sin \theta\right)+P_{3}\left(\frac{d}{2}+c+b+f-h \sin \theta\right) \\
& +P_{4}\left(\frac{b}{2}+f-h \sin \theta\right)-\frac{1}{2}\left(q l+G_{B}\right) l \cos \theta=0 \\
& \sum F_{x}=0: T_{A B}-T_{C B}=0, \\
& \sum F_{y}=0:-R_{A B} a-P_{1} f-P_{2} c-P_{3} d-P_{4} b-R_{C B} a+q l+G_{B}=0
\end{aligned}
$$

The length of key block B is the sum of the abandoned roadway's width, the failed pillar's width, $f$, and the periodic weighting interval [6], which is

$$
\begin{aligned}
& l=b+c+f+l^{\prime}, \\
& l^{\prime}=h \sqrt{\frac{R_{T}}{3 q}},
\end{aligned}
$$

where $R_{T}$ is the tensile strength of the main roof, $\mathrm{kN} / \mathrm{m}$.

$f$ can be calculated by the following equation [21], $(1.97 \mathrm{~m})$.

$$
f=\frac{M \lambda}{2 \tan \phi_{0}} \ln \left[\frac{\lambda\left(\sigma_{y} \cos \alpha \tan \phi_{0}+2 c_{0}-M \gamma_{0} \sin \alpha\right)}{\lambda\left(2 c_{0}-M \gamma_{0} \sin \alpha\right)+2 P \tan \phi_{0}}\right],
$$

where $\alpha$ is the inclination of the coal seam, $2^{\circ} ; \gamma_{0}$ is the bulk density of the coal seam, $14 \mathrm{kN} / \mathrm{m}^{3} ; P$ is the horizontal supporting force on the left side of the abandoned roadway, $0.25 \mathrm{MPa}$; and the other parameters are consistent with equation (2).

Using the limit equilibrium theory, we transformed the $\mathrm{O}^{\prime}-x^{\prime}-y^{\prime}$ coordinate into the $\mathrm{O}-x-y$ one, as shown in Figure 8. Then, $q(x)$ can be given as follows:

$$
\begin{aligned}
q(x)= & -\left(\frac{c_{0}}{\tan \phi_{0}}+\frac{P}{\lambda}\right) e^{-2 \tan \phi_{0} / M \lambda(x+h \cos \theta+H+M / 2)} \\
& +\frac{c_{0}}{\tan \phi_{0}}-f+h \sin \theta .
\end{aligned}
$$

From the following equation (10), it is obvious that $\Delta \mathrm{u}$ is related to $H, M$, and $K_{P}$, where $h 0$ is the thickness of the immediate roof, $m$; $K_{P}$ is the loosening coefficient of the broken rock seam, 1.5. Then, the calculation of $a$ can be given with the geometric relationship after the key block rotation:

$$
\begin{aligned}
\Delta u & =M-h_{0}\left(K_{P}-1\right), \\
\sin \theta & =\frac{\Delta u}{l}, \\
a & =\frac{1}{2}(h \cos \theta-\Delta u) .
\end{aligned}
$$

To ensure that the key block B does not occur sliding instability and rotational instability, shear forces $R_{A B}$ and $R_{C B}$ need to meet inequality as in equation (12). Stress at the key block hinged joint $\sigma$ and the compressive strength of the rock block $\sigma_{c}$ needs to meet inequality.

$$
\begin{gathered}
\sigma=\frac{T_{A B}}{a} \leq \sigma_{c}, \\
R_{A B} \leq T_{A B} \tan \phi .
\end{gathered}
$$

Now there are three unknowns $(T, R, P 4)$, but two effective equations (equations (5) and (7)), and based on the previous support experience and the dichotomy mathematical method, we could try to validly give $P 4$ (which means we could give two values, $\mathrm{P}_{4} 1$ and $\mathrm{P}_{4} 2$, each value corresponds to a $T$ and $R$, if the $T$ and $R$ corresponded to $\mathrm{P}_{4} 1$ is unqualified for the equation (11), and $\mathrm{P}_{4} 2$ 's is overqualified for the condition, then, we take the value in the middle of the two to verify its $T$ and R's qualification, then, the possible solution interval is narrowed, and so on, and the middle value is always taken to confirm its $T$ and $\mathrm{R}$ ), when $P 4$ was given to $1073 \mathrm{kN} / \mathrm{m}$, the $T_{A B}$ and $R_{A B}$ could satisfy both the inequality equations (11) and (12), which means key block B does not occur slipping instability and rotational instability.

\section{Numerical Simulation}

To further grasp the stress distribution and deformation law of the rock mass around the stope and the roadway during the 12404-1 long-wall face passes through abandoned roadway 2, the UDEC numerical simulation software is used to assist this study, which could provide a basis for the support design of the roadway.

4.1. Model Establishment. The model uses plane strain. It has a calculated length of 200 meters and a height of 200 meters. The model is divided into quadrilateral grids, with a total of 3,000 grids. The thickness of each rock layer takes the actual value. The simulated mining height is 2.5 meters. According to the lithology of the sedimentary rock, 2,500 


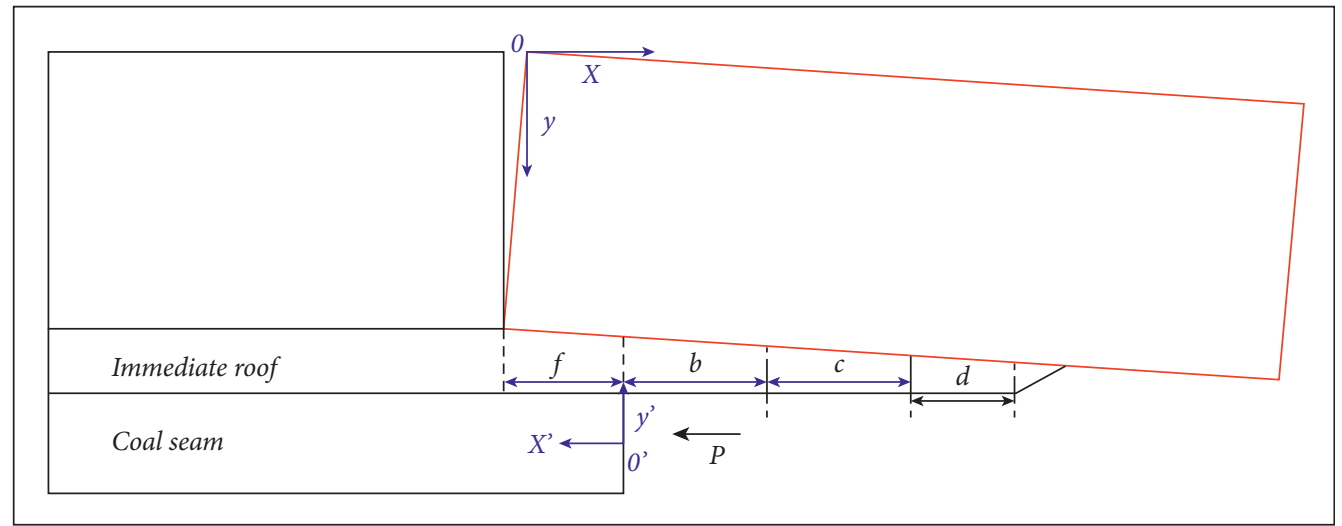

Figure 8: Coordinate conversion.

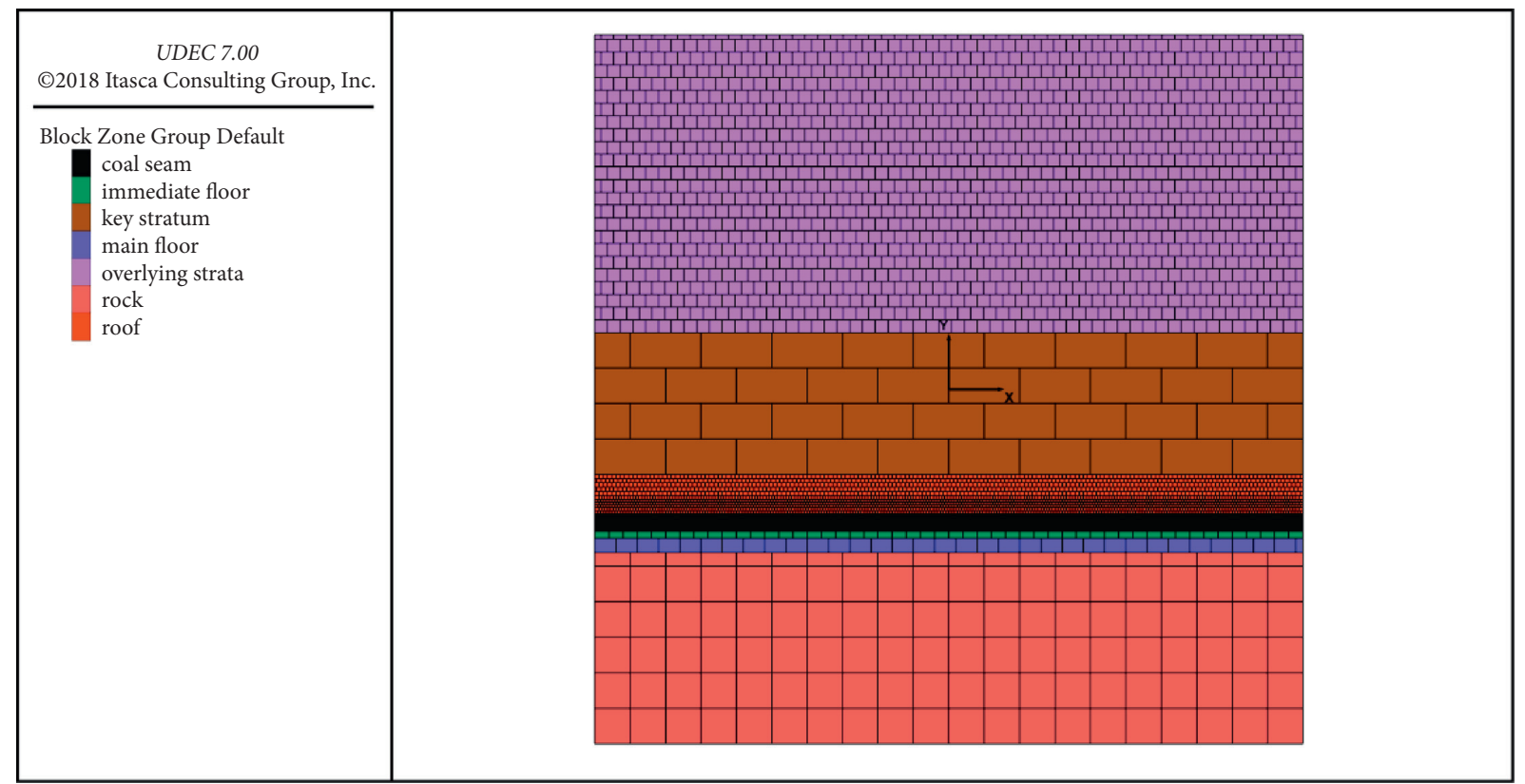

FIGURE 9: Numerical simulation model.

TABle 1: Physical-mechanical parameters of coal and rock layers.

\begin{tabular}{|c|c|c|c|c|c|c|}
\hline Lithology & $\begin{array}{l}\text { Density } \\
\left(\mathrm{kg} / \mathrm{m}^{3}\right)\end{array}$ & $\begin{array}{c}\text { Elasticity modulus } \\
(\mathrm{GPa})\end{array}$ & Poisson ratio & Cohesion (MPa) & $\begin{array}{c}\text { Friction angle } \\
\left({ }^{\circ}\right)\end{array}$ & $\begin{array}{c}\text { Tensile strength } \\
(\mathrm{MPa})\end{array}$ \\
\hline$\# 12$ coal & 1350 & 8.3 & 0.32 & 2.7 & 24 & 1.2 \\
\hline Mudstone & 2431 & 8.9 & 0.26 & 1.25 & 29 & 0.7 \\
\hline Argillaceous siltstone & 2843 & 33.4 & 0.235 & 3.25 & 37 & 1.9 \\
\hline Fine-grained sandstone & 2560 & 25 & 0.159 & 2.51 & 42 & 2.0 \\
\hline $\begin{array}{l}\text { Medium-grained } \\
\text { sandstone }\end{array}$ & 2457 & 13.5 & 0.123 & 2.16 & 38 & 1.1 \\
\hline Coarse-grained sandstone & 2710 & 30 & 0.22 & 2.73 & 36 & 1.6 \\
\hline
\end{tabular}

horizontal and vertical joints were set up, as shown in Figure 9. The upper of the model adopts the stress boundary condition, the left and right and the bottom adopt the displacement boundary condition to, respectively, restrict the horizontal and the vertical displacements. The model adopts the Mohr-Coulomb criterion. The physical-mechanical parameters of each rock stratum obtained by RocData software are shown in Table 1 . RocData can estimate the physical-mechanical parameters of various rock materials through laboratory data fitting or through the built-in typical rock stratum parameter range table in the software. 


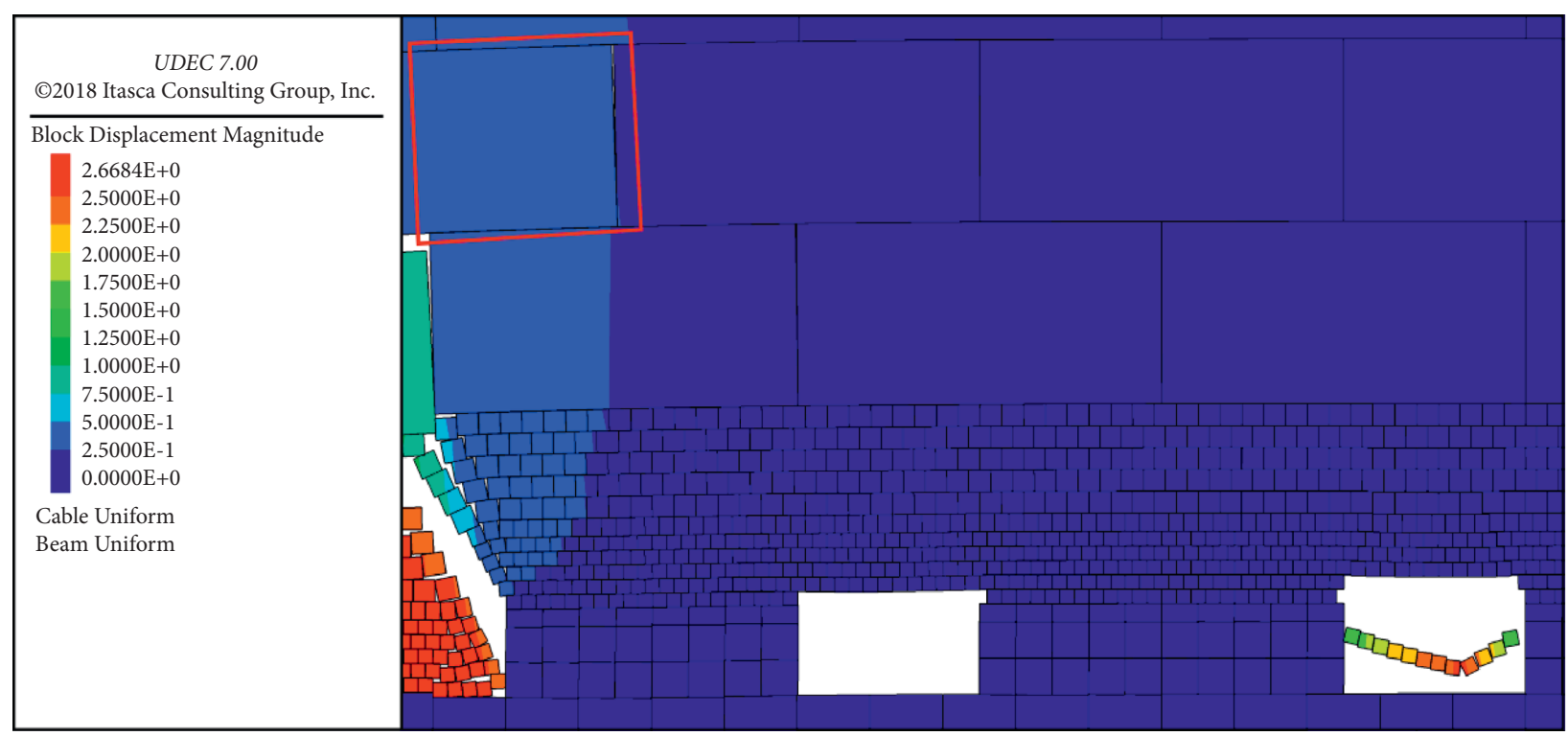

(a)

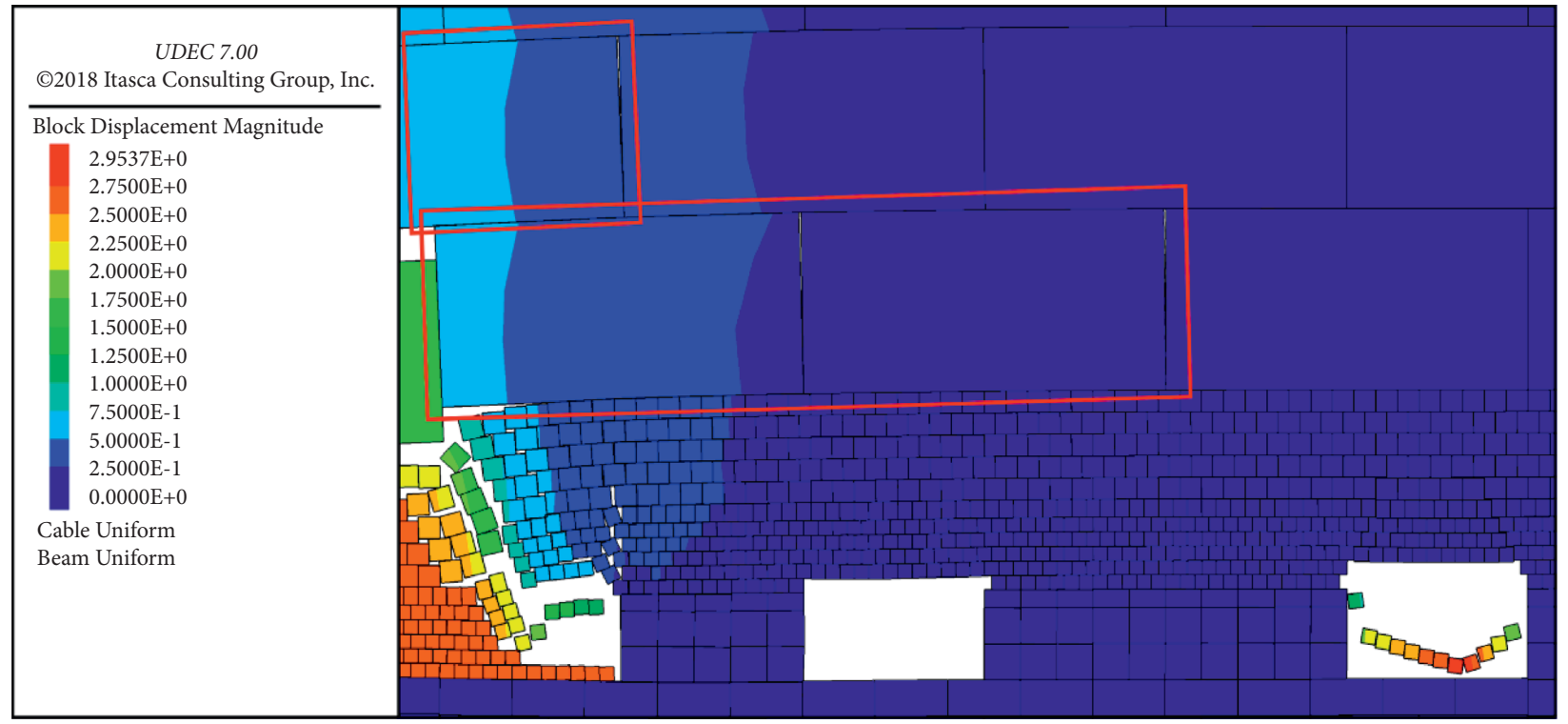

(b)

Figure 10: Continued. 


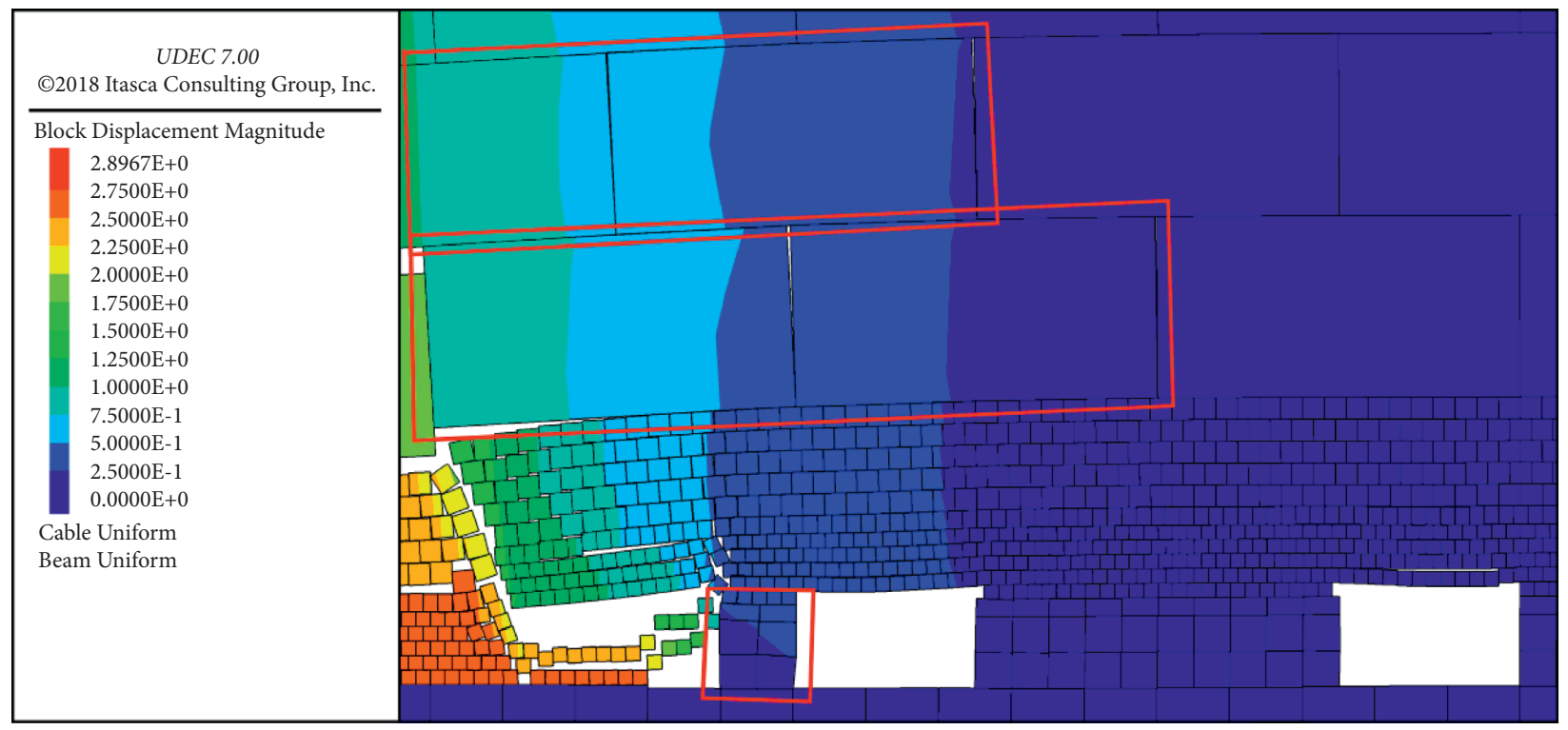

(c)

Figure 10: Failure of coal pillar and advanced breaking. (a) $8 \mathrm{~m}$. (b) $5 \mathrm{~m}$. (c) $2 \mathrm{~m}$.

4.2. Failure of Coal Pillar and Mechanism of Advanced Breaking. When the width of the coal pillar is $8 \mathrm{~m}$, as shown in Figure 10(a), the high key stratum just above the coal pillar began to break in a small span, but the shape of the coal pillar was intact, and there was no obvious deformation. When the working face advances forward for another $3 \mathrm{~m}$, the width of the coal pillar is taken as $5 \mathrm{~m}$, as shown in Figure 10(b), and both the high-position key stratum and the low-position key stratum are broken in advance. The breaking position goes deeper into the coal body, and the right side of the coal pillar is a little bit deformed. When the width of the coal pillar is $2 \mathrm{~m}$, in Figure 10(c), the whole key stratum above the coal pillar is obviously broken, and the high-position key layer has a wider range of advanced breaking. At this time, the deformation of the coal pillar along the $X$ and $Y$ directions is obvious, indicating that it has lost its bearing capacity.

The whole process shows that when the width of the coal pillar has not reached its critical value, the stress it bears is still within its strength limit range. At this time, the coal pillar has a certain bearing capacity, and the working face will continue mining as usual, which means the roof breaks behind the working face. When the coal pillar width reaches the critical value, the stress it bears exceeds its strength limit, resulting in failure and loss of its bearing capacity. The whole left side of the roadway is similar to a goaf because of the failure of the coal pillar. At this time, the roof around the roadway suddenly loses support, resulting in fracture, rotation, and subsidence, and its fracture will be ahead of the coal mining face, that is, the advanced breaking.

\section{Roof Controlling Technology}

5.1. Pumping Pillar Size Determination. We considered the strength of the supporting material and its cutability and finally determined the supporting technology as a "pumping pillar + reinforcing anchor." The pumping pillar is mainly made of silica fume, mineral powder, silicate, cement, etc. mixed in a certain proportion. After determining the proportion of each ingredient, and measuring the laboratory strength of the supporting material, generally, we thought that the formula for calculating the supporting strength of the pumping pillar is as follows:

$$
Q=\pi R^{2} \times q_{\text {pillar }} \times f_{s} \times \frac{1}{b},
$$

where $Q$ is the strength of the pumping pillar, $\mathrm{kN} / \mathrm{m} ; R$ is the radius of the pumping pillar, $m$; $q_{\text {pillar }}$ is the laboratory strength of the pumping pillar, $15 \times 10^{6} \mathrm{~N} / \mathrm{m}^{2} ; f_{\mathrm{s}}$ is Gu's coefficient of the supporting structural strength of the pillar, $0.9-1$; and $b$ is the width of the abandoned roadway, $5 \mathrm{~m}$.

According to the theoretical result calculated in Section 3.3 , the empty roadway should provide at least $1073 \mathrm{kN} / \mathrm{m}$ supporting force to ensure the stability of the key block, that is to say, the radius of the pumping pillar must meet the following formula:

$$
\pi R^{2} \times q_{\text {pillar }} \times f_{s} \times \frac{1}{b} \geq 1073 \frac{k N}{m} .
$$

We took $f_{s}$ as 0.95 . Substituting $f_{s}$ into formula (14), we get that: $R \geq 0.346 \mathrm{~m}$ and took it $0.35 \mathrm{~m}$.

5.2. Roof Supporting Technology of Abandoned Roadway. The parallel roadway adopts the support method of “ $\Phi 22.4 \mathrm{~mm} \times 8000 \mathrm{~mm}$ anchor cable $+4.6 \mathrm{~m} \mathrm{~W}$ steel belt + pumping pillar." Three anchor cables are arranged in each row, with a row spacing of $1.5 \mathrm{~m}$. The diameter of the pumping pillar is $700 \mathrm{~mm}$. A row of pumping pillars is set up within $25 \mathrm{~m}$ at both ends of the abandoned roadway, with a spacing of $3 \mathrm{~m}$, and two rows of pumping pillars in the 


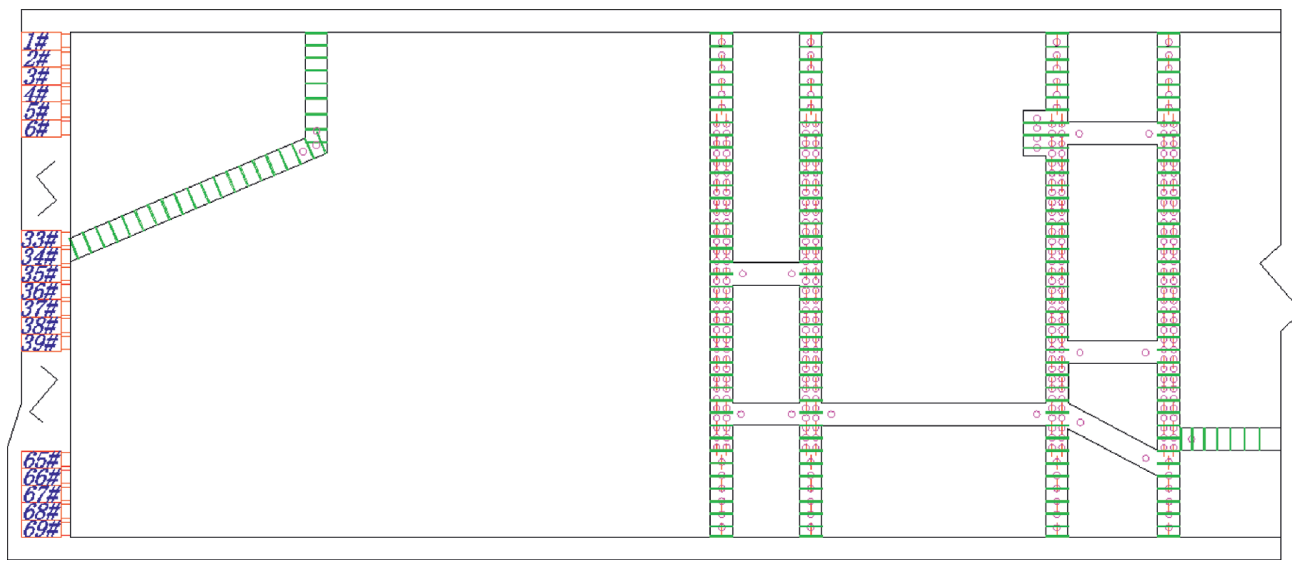

$\square$ Hydraulic support

Reinforcing anchor $+W$ steel belt

Pumping pillar

FIGURE 11: Layout of the roadway supporting technology.

TABLE 2: Supporting parameters of roadway roof.

\begin{tabular}{lccc}
\hline Roadway & $\begin{array}{c}\text { Cross-sectional } \\
\text { diagram }\end{array}$ & Supporting material & Specification \\
\hline & & Anchor cable & $\Phi 22.4 \times 8000 \mathrm{~mm}$ \\
Abandoned roadways $1,2,3,4,5,7$, and 8 & $5 \mathrm{~m} \times 3 \mathrm{~m}$ & W steel belt & $300 \times 300 \times 12 \mathrm{~mm}$ \\
& & Top net & Wire net $45 \times 4500 \times 230 \times 2.2 \mathrm{~mm}$ \\
& & Pumping pillar & $\Phi 700 \mathrm{~mm}$ \\
\hline
\end{tabular}

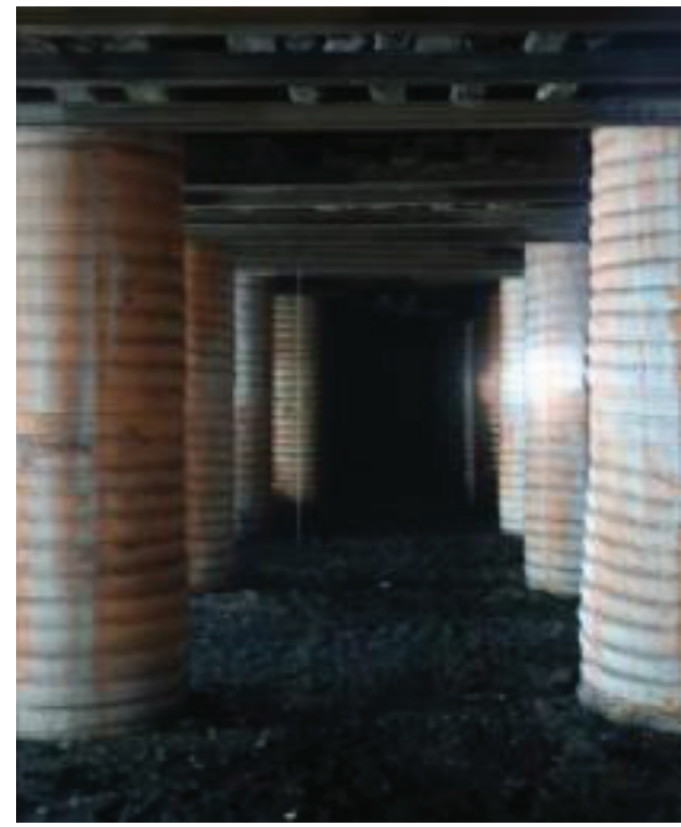

(a)

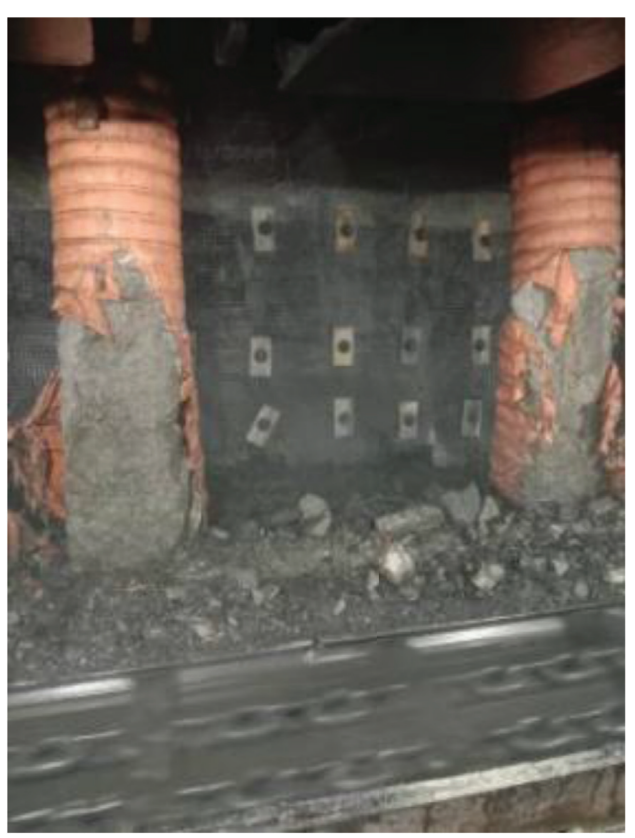

(b)

Figure 12: Pumping pillar supporting field model.

middle of the abandoned roadway, with the spacing of $2.5 \mathrm{~m} \times 2.5 \mathrm{~m}$. A row of pumping pillars is added in the chamber with the spacing of the middle one. A pillar is set at the end of each connecting roadway $1 \mathrm{~m}$ away from the abandoned roadway. The layout of the roadway supporting technology is shown in Figure 11. The supporting 


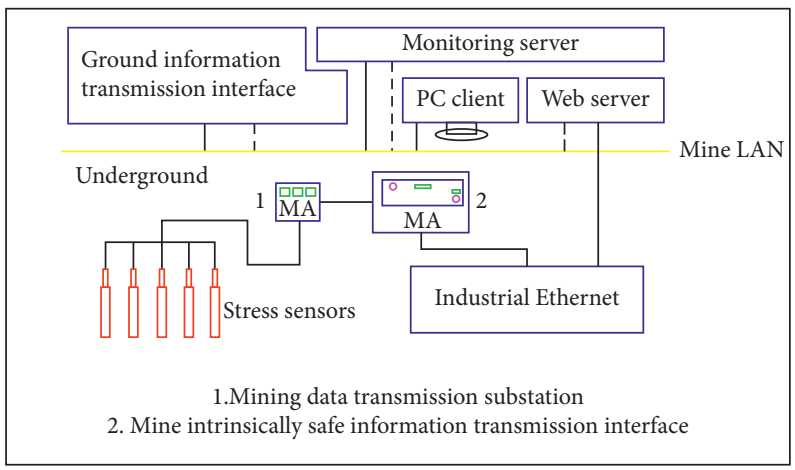

FIGURE 13: Uroica ground stress observation system.

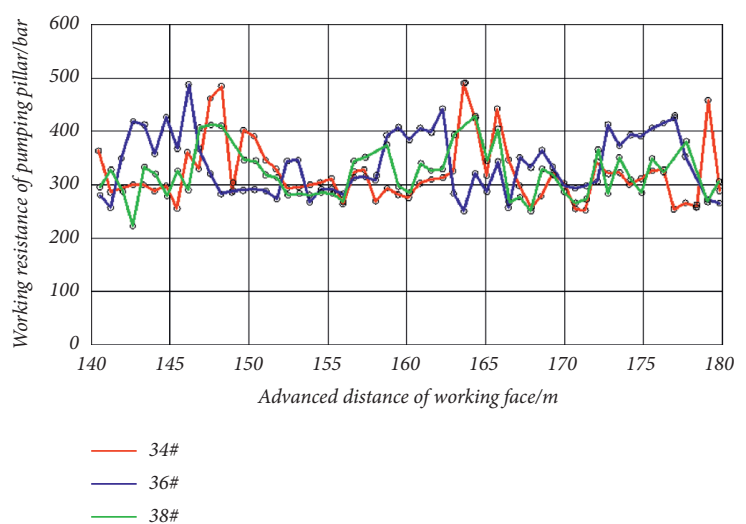

FIGURE 14: Working resistance monitoring of pumping pillars.

parameters are shown in Table 2. In Figure 12, the left one is the situation before the long-wall face passes through the abandoned roadway, and the right one is after. The unobvious failure of the pumping pillar indicates that this kind of new support design well achieved the engineering purpose.

5.3. Measurement of Supporting Effectiveness. The 12404-1 long-wall face adopted the Uroica ground stress observation system for the monitoring, Figure 13. Via the data that came from the stress sensors embedded in the pupping pillar, Figure 14 shows the supporting resistance curve of $34 \#, 36 \#$, and $38 \#$ supports when the long-wall face passes through the abandoned roadways 2 and 3 . When the long-wall face advances $154 \mathrm{~m}$ and passes through abandoned roadway 2, the roof breaks in advance, compared with no passing through abandoned roadway 2 , and the working resistance of the support does not significantly increase. When the long-wall face advances $177 \mathrm{~m}$ and begins to pass through the abandoned roadway 3 , the roof on the middle of the long-wall face breaks in advance again, except the 34\# support, which was set at the middle of the long-wall face, the highest of its working resistance reached 470 bar, and others were basically constant in the process. It shows that the pumping pillar has a better support effect on the roof of the abandoned roadway, and it did not cause roof instability.

\section{Conclusions}

(1) This study analyzed the distribution characteristics of the vertical stress of the pillar and determined the critical width of the pillar is about $4.75 \mathrm{~m}$. The mechanism of the roof advanced breaking is revealed, and a more refined theoretical model is established to analyze the stability of the key block when the long-wall face passes through the abandoned roadway and accordingly determine the support force for the roof of the abandoned roadway for $1073 \mathrm{kN}$ per meter.

(2) This study adopted the mathematical method of controlling variables and dichotomy, that is, in the case of three unknowns $(T, R, P 4)$ and two equations, first, validly assumed the support force $P 4$ according to the previous experience, second, solved the horizontal force $T$ and the shear force $R$ for key block B, checking the effectiveness of $T$ and $R$, and finally, verified whether $T$ and $R$ satisfy the sliding instability and rotation instability conditions, determining the supporting force of the roadway roof to maintain the stability of key block B.

(3) According to the geological conditions of the Wulanmulun coal mine, models were established to simulate the vertical stress of the coal pillar and the advanced breaking mechanism of the roof when the long-wall face passes through the roadway. It is 
concluded that when the width of the coal pillar is about 5 meters, the bearing capacity of the pillar will dramatically drop, causing the whole roof to break in advance, which is in good agreement with the theoretical analysis.

(4) According to the results of theoretical analysis and numerical simulation, a compound surrounding rock control technology is proposed during the longwall face passing through the roadway, that is, pumping pillar supporting and anchor cable supporting. The monitoring analysis of ground pressure and support effectiveness has achieved the expectation.

\section{Recommendations}

From the theoretical analysis, it is not difficult to see that when the working face is close to the abandoned roadway within a few meters, the roof of the working face will break in advance. Without the implementation of corresponding measures, it will inevitably lead to serious problems such as coal rib spalling, support crushing, roof falling, and rock burst. Such engineering problems should be paid attention to. However, due to the formation of key blocks after the breaking of the key stratum, the author believes that the core to solve this kind of problem is to focus on the main key block. As long as the stability of the main key block is maintained, the normal mining of the working face can be guaranteed. Numerical simulation to verify the theoretical analysis, theoretical analysis to support the supporting technology design, and field monitoring to verify the supporting effectiveness are the core of this study. However, due to the difference of advanced breaking performance in different geology, this study only provides a thinking perspective.

\section{Data Availability}

No data were used to support this study.

\section{Conflicts of Interest}

The authors declare that they have no conflicts of interest.

\section{References}

[1] Z. H Xu, Y.S Zhao, and H. B Gao, "Several problems of the old mining remnants in longwall fully mechanized mining technology," Journal of China Coal Society, vol. 40, no. S1, pp. 33-39, 2015.

[2] Q. Y Xu, Z. X Ning, and R. S Zhu, "Study on instability mechanism and top control of overfilled roof in fully mechanized caving face," J Min Saf Eng, vol. 36, no. 3, pp. 505-512, 2019.

[3] S. C Gu, B. N Wang, R. B Huang, and Y. Miao, "Method for determining the load on and width of coal pillar at the recovery room end of fully-mechanized longwall mining," Journal of China University of Mining and Technology, vol. 44, no. 6, pp. 990-995, 2015.
[4] Y Li, E. G Zhu, and K. N Zhang, "Mining methods and roof caving mechanism in longwall mining through the abandoned gateroads of small mines," Journal of China Coal Society, vol. 42, no. S1, pp. 16-23, 2017.

[5] S. C. Gu, R. B. Huang, and J. H. Li, "Stability analysis of unmined coal pillars during the pressure adjustment prior to long-wall face transfixion," J Min Saf Eng, vol. 34, no. 1, pp. 60-66, 2017.

[6] S. R Xie, S. J Li, and Z Wei, "Stability control of supportsurrounding rock system during fully mechanized caving face crossing abandoned roadway period," Journal of China Coal Society, vol. 40, no. 3, pp. 502-508, 2015.

[7] J. B Bai and C. J. Hou, "Research on principle of roof stability of abandoned workings and supporting technology," Journal of China Coal Society, vol. 1, pp. 8-11, 2005.

[8] Z. Z Zhang, J. B Bai, Z. T Han, X. Y Wang, Y Xu, and M. Wang, "Roof mechanics analysis and backfill technology for abandoned roadway," J Min Saf Eng, vol. 30, no. 2, pp. 194-198, 2013.

[9] T. Zhao and C. Liu, "Roof instability characteristics and pregrouting of the roof caving zone in residual coal mining," Journal of Geophysics and Engineering, vol. 14, no. 6, pp. 1463-1474, 2017.

[10] C Liu, P. L Gong, and K Wang, "Roof stability for repeated mining workface passing through abandoned parallel gateway," Journal of China Coal Society, vol. 40, no. 2, pp. 314-322, 2015.

[11] C Liu, Z. Q Yang, and P. L Gong, "Mechanism and control technology of supports crushing induced by main roofs breaking ahead of workface when crossing abandoned roadway," Journal of China Coal Society, vol. 42, no. 8, pp. 1932-1940, 2017.

[12] K Wang, P. L Gong, X. Q Zhang, Q Lian, J Li, and D. Duan, "Characteristics and control of roof fracture in caving zone for residual coal mining face," Chinese Journal of Rock Mechanics and Engineering, vol. 35, no. 10, pp. 2080-2088, 2016.

[13] X. Zhang, P. Gong, K. Wang, J. Li, and Y. Jiang, "Characteristic and mechanism of roof fracture ahead of the face in an LTCC panel when passing an abandoned roadway: a case study from the Shenghua Coal Mine, China," Rock Mechanics and Rock Engineering, vol. 52, no. 8, pp. 27752788, 2019.

[14] Y. Du, G. Feng, Y. Zhang, X. Zhang, Y. Zhai, and J. Bai, "Pressure reduction mechanism and effect of working face passing through abandoned roadway by roof presplit," Energy Science \& Engineering, vol. 8, no. 10, pp. 3502-3513, 2020.

[15] Q. Wang, H. Gao, H. Yu, B. Jiang, and B. Liu, "Method for measuring rock mass characteristics and evaluating the grouting-reinforced effect based on digital drilling," Rock Mechanics and Rock Engineering, vol. 52, no. 3, pp. 841-851, 2019.

[16] Q. Wang, B. Jiang, R. Pan et al., "Failure mechanism of surrounding rock with high stress and confined concrete support system," International Journal of Rock Mechanics and Mining Sciences, vol. 102, pp. 89-100, 2018.

[17] M. G Qian, P. W Shi, and J. L Xu, Ground Pressure and Strata Control, China University of Mining and Technology Press, Xuzhou, 2010.

[18] C. He and N. Ma, "Stress in in-seam roadway sides and limit equilibrium zone," Journal of China Coal Society, vol. 4, pp. 21-29, 1989, in Chinese.

[19] J. L Xu and M. G Qian, "Method to distinguish key strata in overburden," Zhongguo Kuangye Daxue Xuebao/Journal of China University of Mining \& Technology, vol. 29, no. 5, pp. 463-467, 2000. 
[20] L. Chang, J. Zhang, and Z. Yang, "Mechanism of advance fracture of main roof and its control technology when workface crossing abandoned roadway," Rock and Soil Mechanics, vol. 39, no. 4, pp. 1411-1421, 2018, in Chinese.

[21] Ke Yang and Q. liu, "Study on distribution laws of stress in inclined coal pillar for fully-mechanized top-coal caving face," Chinese Journal of Rock Mechanics and Engineering, vol. 25, no. 3, pp. 545-549, 2006, in Chinese. 